\title{
The Great Valparaiso Fire and Fire Safety Management in Chile
}

\author{
Pedro Reszka* and Andrés Fuentes, Energy Conversion and Combustion Group, \\ Departamento de Industrias, Universidad Tecnica Federico Santa Maria, \\ Valparaiso, Chile
}

\begin{abstract}
The Great Valparaiso Fire started as a wildfire on the outskirts of the city. The fire spread through the wildland-urban interface towards the city. In 5 days, it claimed the lives of 15 people, injured more than 500 people, destroyed over 2,900 homes, burned over 1,000 ha, and displaced approximately 12,500 people. In this Letter to the Editor, several issues that facilitated the tragic events are discussed.
\end{abstract}

Keywords: WUI fires, Wildfires

Sir,

The Chilean city of Valparaiso has a rich cultural and economic history of almost 500 years. Located in central Chile, its metropolitan area has a population of just under one million inhabitants, and is considered to be one of the most important seaports in the South Pacific. Due to the geography of the city and urban sprawl, most of the population lives on more than 40 hills that overlook the Valparaiso Bay, with some homes being built on steep slopes and in other cases built in small valleys or ravines which are formed between different hills. The vegetation around the city is mainly shrubland with some dense pine and eucaliptus forests whose growth is favored by the humid conditions that often occur in the area.

According to official data, the catastrophic events that unfolded during what is now called the Great Valparaiso Fire claimed the lives of 15 people, injured more than 500, destroyed more than 2,900 homes, burned more than 1,000 ha, and displaced approximately 12,500 people. The economic losses have not yet been assessed. What started as a forest fire in the upper parts of the La Pólvora hill $\left(-33.095^{\circ}\right.$ Lat., $-71.587^{\circ}$ Long.) quickly spread through the wildland-urban interface (WUI) towards the city. The fire, which started in the evening of April 12, spread mostly downhill, and in 5 days affected neighborhoods located in 10 of the city's hills. Flame spread was favored by high SE winds (i.e. blowing towards the Pacific Ocean, cf. Figure 1), but also by poor urban planning and WUI management. The Great Valparaiso Fire has been classified as the worst fire in the history

\footnotetext{
* Correspondence should be addressed to: Pedro Reszka, E-mail: pedro.reszka@usm.cl
} 


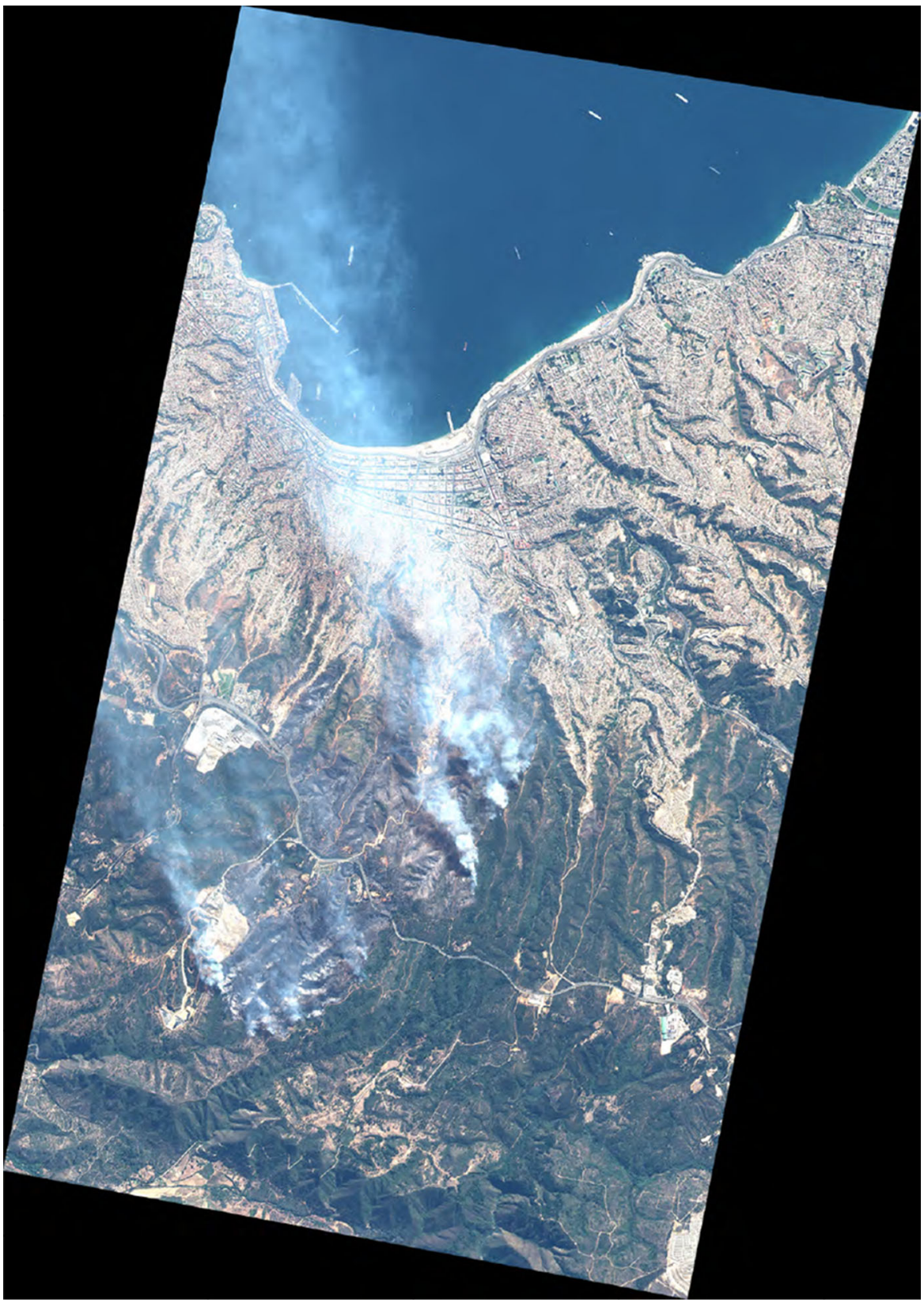

Figure 1. Satellite image of the fire (visible spectrum). The bay of Valparaiso can be seen at the top of the picture. The smoke plumes indicate the predominant direction of the wind during the fire. Image by Chilean satellite FASAT-Charlie. (SAF, Chilean Air Force. 
of the city, devastating a significant portion of the city and the neighboring wildland (see Figures 2 and 3). These events have prompted us to share some thoughts with the readers of Fire Technology, which we hope would help in preventing these types of events.

The first question that comes to mind is how can a fire affect large portions of a city in the Twenty-first Century, in a manner reminiscent of the great fires in European cities centuries ago. Most of the homes that were affected by the fire were low income housing, with substandard building methods, high density of houses, heavy use of lightweight construction materials, no official approvals, and poor access to basic services. Many of these houses were built on properties without deeds, with the owners illegally occupying lands, in what unfortunately is still a recurrent practice in our country. The fuel load was high not only because of the high density of houses, but also because of trash that accumulated in empty lots. This caused the fire to spread rapidly downhill. These catastrophic events reflect many of the inequalities that are still present in our country, but nevertheless one should not be led to think that the fire attained catastrophic characteristics only because it affected low income neighborhoods. The Chilean building codes still have no requirements for flammability and flame spread properties of building materials, and issues such as fire spread to neighboring structures are not considered. Even though the Chilean fire brigades are well trained and have good appliances and equipment, they do not have jurisdiction on building approvals, and the Chilean legislation does not have a figure like a Fire Marshall to enforce building codes and ensure the fire safety of the built environment.

This is not the first incident where fires in the WUI spread to urban areas in Valparaiso or other Chilean cities. WUI fires are becoming more common and causing greater losses in Chile and the rest of the world [1]. In Chile, the WUI represents a gray area in terms of jurisdiction. Conaf, the Chilean government agency that manages forestry and the national park system, is in charge of fighting forest fires and managing fire safety issues in wildland areas. It has effective fire brigades that carry out fire prevention measures as well, like cleaning forests and maintaining firebreaks. Conaf claims that the fire safety management of the WUI is the responsibility of the municipalities, which is contested by the mayors. Very often the municipalities lack the resources, the technical knowledge and the drive to maintain clean WUIs. There have also been claims that several reports indicating the fire risks of these areas were forwarded to the authorities, and that no actions were taken. This shows the need for a city-wide fire safety authority, with clear jurisdictions, with enforcement capabilities, and with the ability to assess fire risks and take measures to mitigate these risks.

Poor urban planning is a problem that affects most Chilean cities. During the Great Valparaiso Fire, there were water supply problems for the fire brigades, but also the fire appliances had trouble accessing the fire fronts, especially due to the narrow roads with sharp turns. The fire brigades also faced the crowds that were evacuating from the burning areas. Due to the steep terrain, many areas had only one access road, and this clearly represents a challenge for urban design in terms of emergency situations. Again, it must be noted that most of the neighborhoods involved in the fire had substandard conditions, but that should not be an excuse 


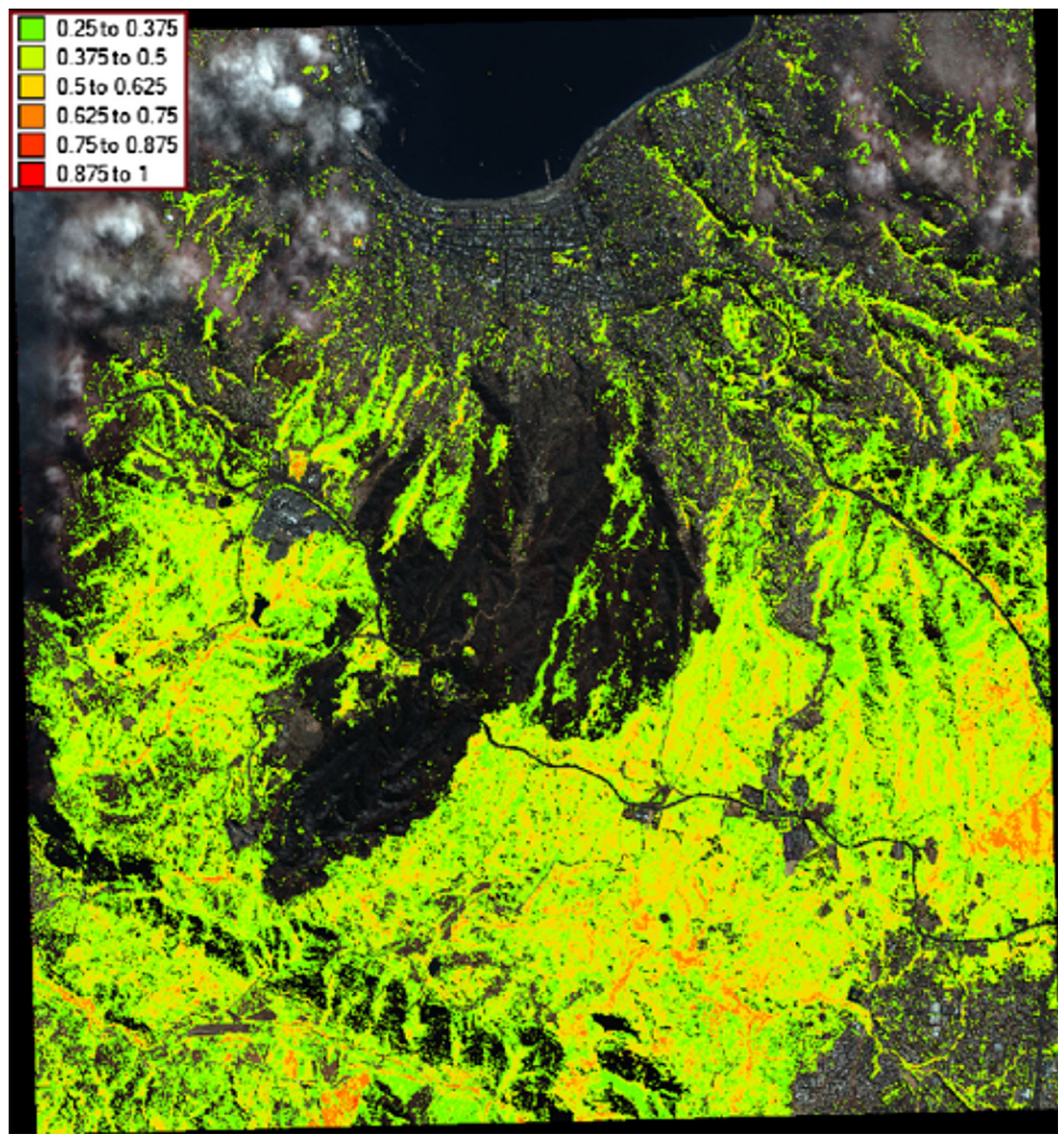

Figure 2. Normalized difference vegetation index (NDVI) of the area affected by the fire. NDVIs closer to 1 indicate denser vegetation. The black areas at the center of the image correspond to the burned area. Image captured by a Pleiades satellife, CNES, France, and made available to Chilean authorities by the International Charter Space and Major Disasters. OCIREN, Ministry of Agriculfure and ONEMI, Ministry of the Interior, Chile.

for a lack of adequate access roads that are wide enough to accommodate both evacuees and emergency response personnel. But fire safe urban planning also has to do with ensuring adequate supplies of fire water, with managing the fuel load of empty lots, with prevention of fire spread or with WUI management, among other issues. 


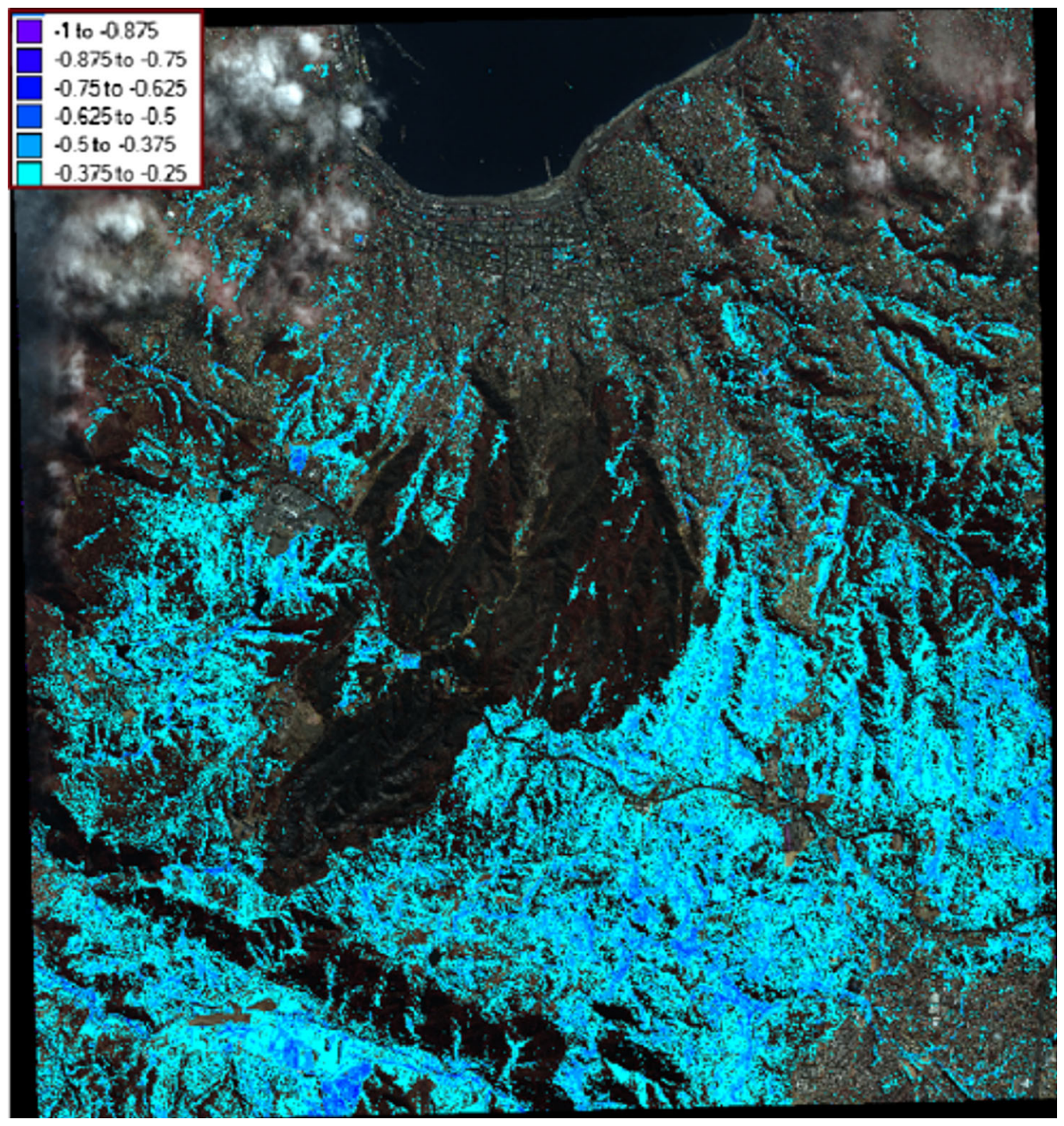

Figure 3. Normalized difference water index (NDWI) of the area affected by the fire [3]. Positive values of NDWI indicate green vegetation. The higher the NDWI value, the greater the amount of water in the vegetation. The black areas at the center of the image correspond to the burned area. Image captured by a Pleiades satellite, CNES, France, and made available to Chilean authorities by the International Charter Space and Major Disasters. OCIREN, Ministry of Agriculfure and ONEMI, Ministry of the Interior, Chile.

These situations and problems are probably common in many parts of the world, particularly in developing countries. Chile is expected to become a developed country in the coming decades, and we hope that public safety issues such as these will be addressed. In the near term, things do not appear to be improving. 
Lightweight houses are being built in the same places, and neither the people nor the authorities appear to heed the concerns of those who warn against living in these areas. Chile needs a critical mass of professionals that are competent in fire safety issues, which will be able to drive changes in building codes and legislation. Fire safety research is being carried out by our group and in other Chilean universities, and many young professionals are pursuing degrees related to fire safety in foreign universities. But formal undergraduate-level education on fire safety is still not widespread across the Chilean university system, particularly in architecture and engineering schools. We hope that these catastrophic events will prompt changes in our legislation, building codes, and the way the Chilean society manages fire risks, following examples from other nations [2]. Chile needs more modern building codes and regulations, which will reflect our most desired passage from a developing to a developed nation.

Sincerely yours,

Pedro Reszka and Andrés Fuentes

\section{Acknowledgments}

The authors wish to acknowledge the kind support of the Chilean Air Force's Servicio Aerofotogramétrico, the Oficina Nacional de Emergencia del Ministerio del Interior y Seguridad Publica (ONEMI), Chile and the Centro de Información de Recursos Naturales (CIREN), Chile for providing satellite pictures, NDVI and NDWI images of the Valparaiso area before, during and after the fire.

\section{References}

1. Manzello SL (2014) Special issue on wildland-urban interface (WUI) fires, editorial. Fire Technol 50:7-8. doi:10.1007/s10694-012-0319-0

2. Mutch R, Rogers M, Stephens S, Gill AM (2011) Protecting lives and property in the wildland-urban interface: communities in Montana and southern California adopt Australian paradigm. Fire Technol 47:357-377. doi:10.1007/s10694-010-0171-z

3. Gao BC (1996) NDWI-a normalized difference water index for remote sensing of vegetation liquid water from space. Remote Sens Environ 58:257-266 